\title{
Design and implementation of a modular interactive labyrinth targeted for use in optical education
}

\section{Azaliya Saitgalina, Nadezhda Tolstoba, Daria Butova, Maria Orekhova, Dmitry Lyamets, et al.}

Azaliya K. Saitgalina, Nadezhda D. Tolstoba, Daria V. Butova, Maria K. Orekhova, Dmitry A. Lyamets, Anastasiia D. Kozhina, Vladimir S. Kolomoitcev, Denis N. Shevchenko, Renata S. Krivtcova, Maksim A. Stepanenko, Kirill A. Kochnev, Alina S. Beliaeva, "Design and implementation of a modular interactive labyrinth targeted for use in optical education," Proc. SPIE 10452, 14th Conference on Education and Training in Optics and Photonics: ETOP 2017, 104524D (16 August 2017); doi: 10.1117/12.2266687

Event: 14th Conference on Education and Training in Optics and Photonics, ETOP 2017, 2017, Hangzhou, China 


\title{
Design and implementation of a modular interactive labyrinth targeted for use in optical education
}

\author{
Azaliya K. Saitgalina, Nadezhda D. Tolstoba, Daria V. Butova, Maria K. Orekhova, Dmitry A. Lyamets, \\ Anastasiia D. Kozhina, Vladimir S. Kolomoitcev, Denis N. Shevchenko, Renata S. Krivtcova, Maksim A. \\ Stepanenko, Kirill A. Kochnev, Alina S. Beliaeva \\ ITMO University, 49 Kronverkskiy Prospect, Saint Petersburg, Russia, 197101; \\ Dept. of Applied and Computer Optics
}

\begin{abstract}
Through the creation of a large number of interactive optical projects in pursuit of this goal, the laboratory has realized that the most effective educational approach is one that presents information in a fun, engaging, and informative manner. Hence, the idea for an optical labyrinth was born. This labyrinth allows students to interact with and learn optical phenomena in real time, presenting tangible benefits for ongoing education of optics and photonics in schools and universities.
\end{abstract}

Keywords: training equipment in optics, labyrinth, optical labyrinth, optical interactive labyrinth, interactive education in optics, Modular and Portable labyrinth, Display-Unit interactive labyrinth.

\section{INTRODUCTION}

The Student Research Laboratory for Optical Engineering (SRLO) ${ }^{1}$ at ITMO University is working on inspiring young people to learn more about the science of optics and photonics ${ }^{2}$, and thereby to bring the next generation of scientists into this exciting field of study. The overall design of the project calls for the creation of two interactive labyrinths: one being a simple modular platform used primarily for basic educational tasks, with the other being a more elaborate platform targeted at more complex educational and demonstration tasks ${ }^{3}$. Both are designed with the explicit goals of effectively explaining the laws of light propagation and geometrical optics, ease of transport, and to be used during ITMO Open Photonics Days. At these demonstrations, ITMO staff are able to interact with young people in order to teach them about the nature of light, popularize optics and photonics, and explain the pivotal role that these sciences play in all our lives.

The interactive labyrinth idea itself was formed to enable one of the core tenets of the educational process: that using tasks that call upon the student's creativity and hands-on experimentation approach is key to the process of learning ${ }^{4}$. Not only is this kind of educational approach more likely to hold the students' attention, it also more effectively teaches them the theoretical foundation, practical skills, and the inquisitiveness that is so important to the scientific method.

\section{IMPLEMENTATION}

The design and development of portable devices used for demonstrating various laws of physics allows us to present interactive, hands-on educational opportunities to students; a light-based labyrinth can therefore be used specifically for teaching the fundamental laws of geometric optics. One potential highly-valuable avenue for the presentation of such a labyrinth is a museum of science; after all, museums can be more accurately thought of not as places for the simple storage of information, but rather as locales that facilitate the active transfer of information to people hungry for knowledge. Within that museum setting, you might imagine using the labyrinth to organize special schools, round-table discussions on specific topics, conferences, workshops, or interactive lectures, all serving to increase the public's perception and understanding of science. The addition of branding to one of these optical labyrinths would furthermore change it from being only an educational tool to one that can also represent and popularize ITMO University in general, and the University's optics program in particular, within the public's mind. As such, this effort is highly leveraged not

14th Conference on Education and Training in Optics and Photonics: ETOP 2017, edited by Xu Liu,

Xi-Cheng Zhang, Proc. of SPIE Vol. 10452, 104524D · (c) 2017 ICO, IEEE, OSA, SPIE

CCC code: $0277-786 \mathrm{X} / 17 / \$ 18 \cdot$ doi: $10.1117 / 12.2266687$

Proc. of SPIE Vol. 10452 104524D-1 
only for education, but also for advertisement.

Two different labyrinth designs were created under the "interactive optical labyrinth" project, both used to aid with the educational process, to help students develop practical skills, and to create and maintain students' interest in the field of geometrical optics. The first labyrinth design is a Modular and Portable (MP-labyrinth) one, to be used primarily in introductory-level classes for bachelor students in order to teach the basics of optics. In this design, the "player" is intended to set the optical elements on the field in accordance with the informational cards which explain the behavior of a beam of light as it passes through the prisms, and thereby guide that beam of light throughout the whole optical system in order to reach the screen, which serves as the finish line. It has a light construction and comes prepackaged with an optical kit, an educational poster, an instructional manual, transport case, and a light source. The second design, while still interactive, is meant to be more of a Display Unit (DU-labyrinth) used in conferences, workshops, and other areas targeted at popularization of optics, photonics, and the ITMO brand. It has compound construction and comes with additional components in comparison to the first labyrinth design; in particular, it contains a light receiver which is able to provide real-time feedback on whether the "player" was able to successfully navigate the labyrinth and get the light beam to the corresponding finish line.

The two labyrinths can be used either as a single-player interactive game, or as a competitive team game between two or more participating students. As a result of playing with the labyrinth, the students are studying:

- laws of light propagation in transparent media;

- the laws of reflection of light from mirror surfaces;

- principles of constructing images when light passes through optical systems without taking into account its wave properties;

- the influence of light filters and polarizers on the radiation flux.

As a result of the practical study of discipline, the student must learn to:

- independently conduct an experiment;

- analyze and generalize the observed phenomena and facts;

- use logical and rational thinking to find solutions to problems.

\section{TECHNICAL CHARACTERISTICS}

\subsection{THE MP-LABYRINTH SET CONTENTS}

- MP field - as minimum;

- MP barrier (asymmetric, symmetric, with the optical element);

- light source;

- set of 4 diaphragms with different forms of apertures;

- set of optical elements;

- educational and technical poster;

- manual;

- transport case.

\subsection{THE DU-LABYRINTH SET CONTENTS}

- DU field;

- $\quad$ set of DU barriers (each barrier consists of 5 layers and 1 stem);

- LEDs;

- light source;

- light receiver;

- set of optical elements;

- educational and technical poster;

- manual; 
- transport case.

\subsection{THE LIGHT SOURCE}

- wavelength is $650 \pm 30 \mathrm{~nm}$;

- laser radiation power is $5 \mathrm{~mW}$;

- energy consumption is $60 \mathrm{~mA} / \mathrm{h}$;

- battery capacity is $2800 \mathrm{mAh}$;

- built-in overcharge/discharge protection;

- charger via microUSB connector.

\subsection{THE LIGHT RECEIVER}

- Bluetooth communication frequency range from 2.4 to $2.48 \mathrm{GHz}$;

- transmission power from 0.25 to $2.5 \mathrm{~mW}$;

- sensitivity of $80 \mathrm{dBm}$;

- communication range $10 \mathrm{~m}$;

- maximum data rate: 115200 baud;

- power consumption $50 \mathrm{~mA} / \mathrm{h}$;

- battery capacity is $2800 \mathrm{mAh}$;

- built-in overcharge/discharge protection;

- charger via microUSB connector;

- viewing angle of the reception sensor is $\pm 45^{\circ}$.

\subsection{THE OPTICAL KIT}

- right angle prisms;

- penta prisms;

- half-penta prisms;

- schmidt prisms;

- rhomboid prisms. 


\section{CONSTRUCTION OF AN INTERACTIVE OPTICAL LABYRINTH}

\subsection{MODULAR AND PORTABLE OPTICAL LABYRINTH}

The field structure is shown in fig. 1. It consists of two plates, with a pattern of holes which are used for mounting the barriers. We decided to use two plates for the overall field assembly so that we have the freedom to create either a square playing field or a long rectangular one, which in turn provides more options for the design of the labyrinth itself. The trapezoidal shape of the playing field's junctions is specifically chosen to prevent them from coming apart when the labyrinth is assembled.

The barrier mounting holes within the field are arranged in a staggered pattern -- this allows many variations in the construction of the labyrinth, not only in quantity, but also in complexity.

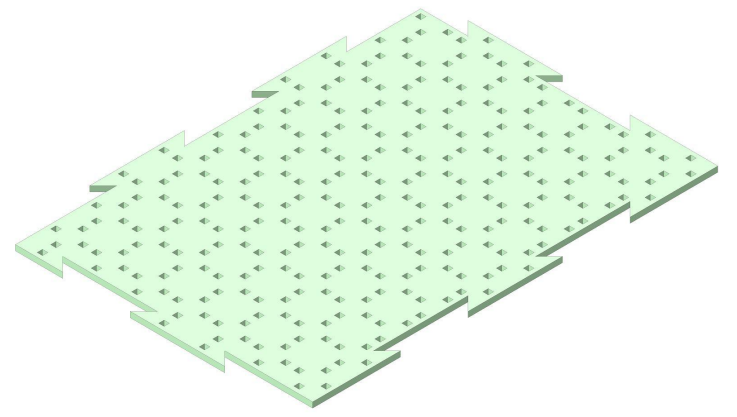

Figure 1 - The MP field

The structure of MP barriers is shown in Fig. 2.

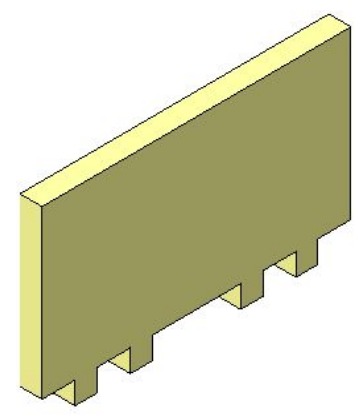

Figure 2 - The sample of MP barrier

During the design process it was decided that field barriers should come in both asymmetric (fig. 3a) and symmetric (fig. $3 b$ ) varieties. In addition, the "finish-line" for the purpose of completing the labyrinth is represented by a double-size standard barrier (fig. 3c). In order to support more complicated labyrinth constructions, an additional set of complex barriers with special elements, such as light filters, polarizers, and mirrors, are also supplied (fig. 3d).
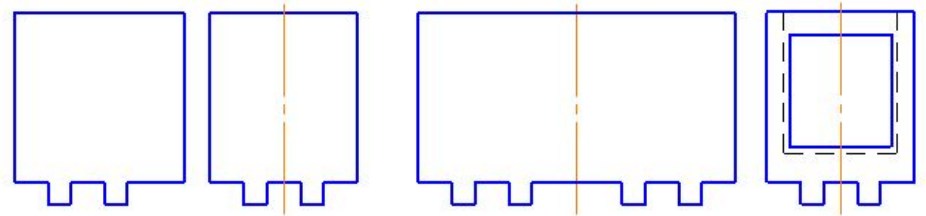

Figure 3. The MP barriers: a) - asymmetrical, b) - symmetrical, c) - double size, d) - complex 


\subsection{DISPLAY-UNIT INTERACTIVE LABYRINTH}

The DU labyrinth field consists of three overlapping layers. The top layer has mount points for the DU barriers and apertures to allow underlying LEDs to be visible. The middle layer contains the wiring harness, electronics cards, a Bluetooth module, and the labyrinth on/off button. The bottom layer has grooves for bolts, arranged around the periphery, which connect all three layers together. The assembly of the three layers and barriers is illustrated in fig. 5 .

One additional key feature of the overall DU labyrinth design is that each layer consists of two interlocking plates; this kind of modularity allows for ease of packing and transportation, as well as making repairs to any layer of the labyrinth much easier.

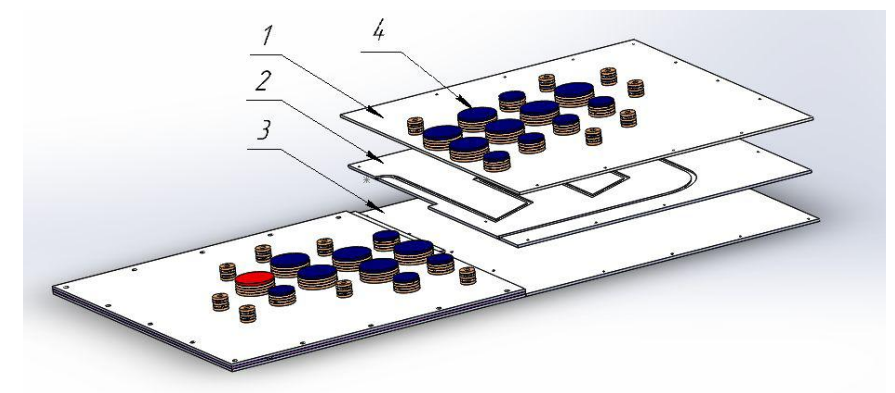

Figure 5. The DU fields and barriers. 1 - top field, 2 - middle field, 3 - bottom field, 4 - barrier

The DU barriers are arranged on the labyrinth field in the shape of the ITMO University logo, as part of the overall branding approach; there are 34 barriers overall, all with varying sizes. Each barrier has a cylindrical structure and consists of several opaque and transparent layers.

Each barrier sits atop an LED embedded in the middle layer. The barrier construction includes not only the rods used to mount it to the playing field, but also an open channel inside to allow the underlying LED to light up the barrier from within (the 3D model that shows this is in fig. 6). All the LEDs will illuminate the barriers when the labyrinth is successfully solved. Also note that the top of each barrier is opaque to ensure that the LED light is diffuse and does not blind the users.

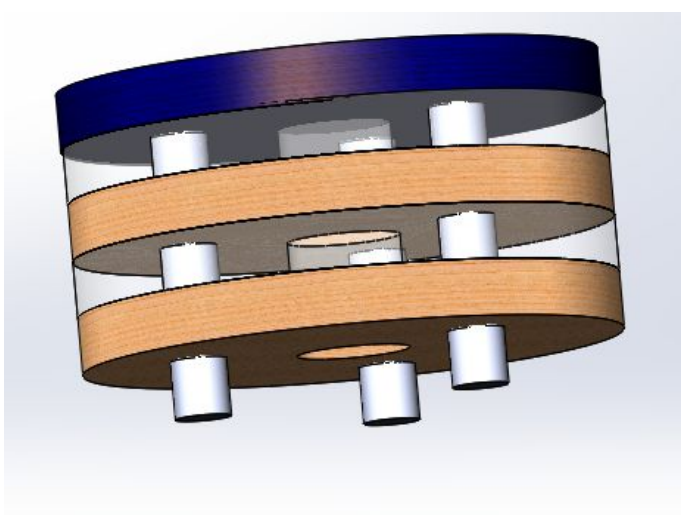

Figure 6. The DU barrier 


\subsection{LIGHT SOURCE}

The outer shell for the light source is made using 3D-printing techniques. This shell includes a built-in rechargeable battery used to power the unit, and allows us to forego having to include power supplies which would increase the unit cost. A micro-USB cable, included within the shell, connected to a battery charging card is used to provide electrical energy for the battery.

Thus, the shell features a stand-alone design that accommodates all the necessary elements, and leads to much easier setup within the labyrinth. This light source shell -- used for both the MP and DU labyrinths -- is shown in fig. 7.
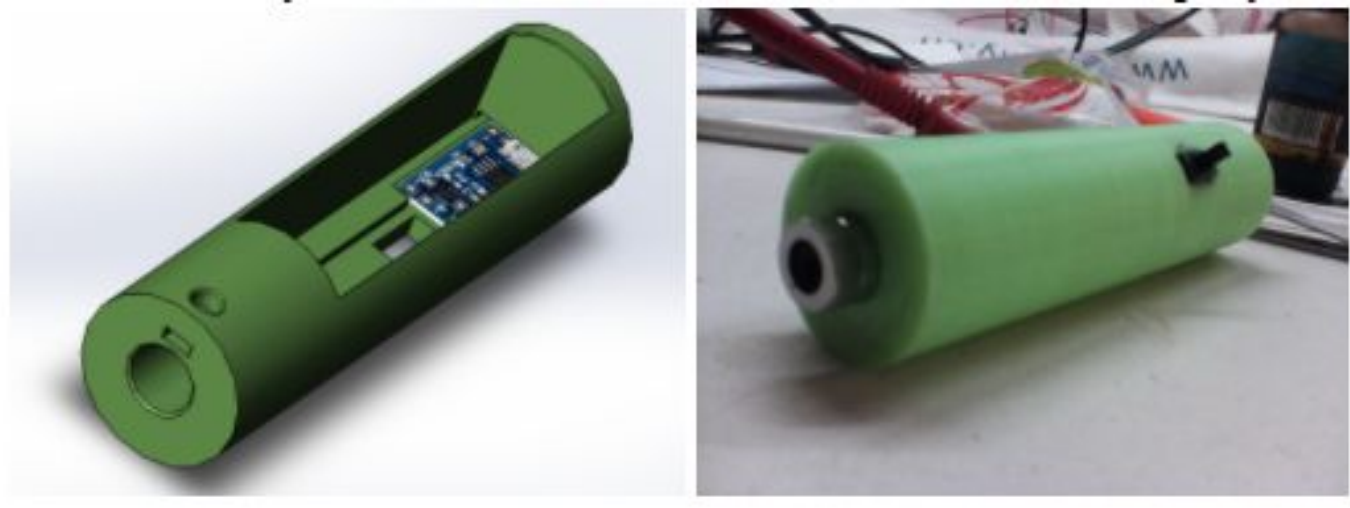

Figure 7. The source's shell, made by 3D-printing

\subsection{LIGHT RECEIVER}

In order to detect and inform the user of a successful solution to the labyrinth, the light receiver must be able to disambiguate the signal produced by the light source (described above) from ambient background radiation. In order to achieve this, the light source must use amplitude modulation at a sufficiently-high frequency such that it is not noticeable to the user; the light receiver, in turn, analyzes the incoming signal and, upon detection of this modulation scheme, knows that the correct source signal is present. When this occurs, the receiver will broadcast the corresponding message via a short-range radio communication protocol, causing the LEDs embedded within the DU labyrinth field to light up.

The structure of the light receiver's shell is currently under development. The shell will accommodate the receiver element, which is sensitive to the light source's signal, a Bluetooth module, which transmits information to the labyrinth field control modules, and a battery.

\subsection{OPTICAL SET}

The choice of the prism set for the labyrinth was based on the following parameters:

- Popularity and frequency of inclusion in most common optical systems currently in use;

- Variability of light reflection from refracting-reflecting surfaces;

- Principles of constructing images when light passes through optical systems.

The following materials were chosen for the prisms, along with reasons for the choice:

- Organic glass TOSN was chosen for producing prisms. It is produced in blocks, in which a number of standard manufactured thicknesses have the required value $(30 \mathrm{~mm})$. This availability reduces the cost of production, since it does not require the processing of material from both sides. In addition, it is a transparent plastic (a kind of polymethylmethacrylate) with high resistance to temperature and chemical effects.

- For the production of prisms from optical glass, the $\mathrm{K} 8$ brand was chosen due to its popularity in the construction of optical systems.

- Quality indices were chosen based on the recommended range of values for reflective prisms, taking into 
account their purpose. Because these prisms are not intended for use in precise instrumentation, the lowest (and, therefore, cheapest) indices were chosen.

\section{THE EFFICIENCY AND RELIABILITY OF THE DESIGN}

First of all, the correct LEDs for the DU labyrinth needed to be chosen, based upon their brightness, rated current, voltage drop, and dimensions. One important characteristic for an LED is its forward current and voltage drop across it; according to the manufacturer's specifications, the BL-L314UBC has a current limit of $30 \mathrm{~mA}$ and a voltage drop of 2.7 $\mathrm{V}$, while the BL-L324URC has a current limit of $25 \mathrm{~mA}$ and a voltage drop of $1.85 \mathrm{~V}$. We decided to limit the forward current to $20 \mathrm{~mA}$ in this design. This yields the total power consumption of all the LEDs to be $1.819 \mathrm{~W}$. Taking into account an additional safety factor of two, total upper ceiling for power consumption for the LEDs is $3.638 \mathrm{~W}$.

The construction of the overall DU labyrinth includes three additional devices which contain electronic components: the light source, the light receiver, and the electronics within the DU field itself. The light source and receiver are both autonomous products with included rechargeable batteries, and thus need not be included in the calculation. The electronics within the DU field include the primary controller, a wireless Bluetooth module, and LED drivers. The LED driver power efficiency is included in the safety factor used in the previous paragraph when computing the power consumption of the LEDs. The power consumption of the primary controller and the Bluetooth module are taken directly from the vendors' provided documentation: the primary controller requires $0.085 \mathrm{~W}$, and the Bluetooth wireless communication module draws $0.165 \mathrm{~W}$. As a result, all inclusive, the power consumption of the DU labyrinth is approximately $4 \mathrm{~W}$, supplied via main-line power at $220 \mathrm{~V}$.

\section{RESULTS}

With support from ITMO University in general, and several instructors from the department of Applied and Computer Optics in particular, we have been able to draft design drawings for, and then manufacture ${ }^{5}$ :

- Modular and Portable labyrinth;

- Display-Unit labyrinth;

- prism optical set;

- light source;

- light receiver.

In addition to the labyrinth components themselves, we have also developed educational posters and assembled packaging materials to be used when transporting and demonstrating the labyrinths.

The first public use of the labyrinth occurred during ITMO Photonics Open Days in China, where entrants solved the labyrinth and collected points for the purpose of enrolling in ITMO University. We have subsequently organized several open classes for foreign students, including France, Vietnam and China in order to teach them the principles of geometrical optics ${ }^{6}$. In addition, we have also successfully used our labyrinth designs in a class titled "Introduction to Optics" for first-year students. The response has been very positive: we have been invited to numerous different social events in order to teach optics in a new and unique way. And this is only the beginning. 

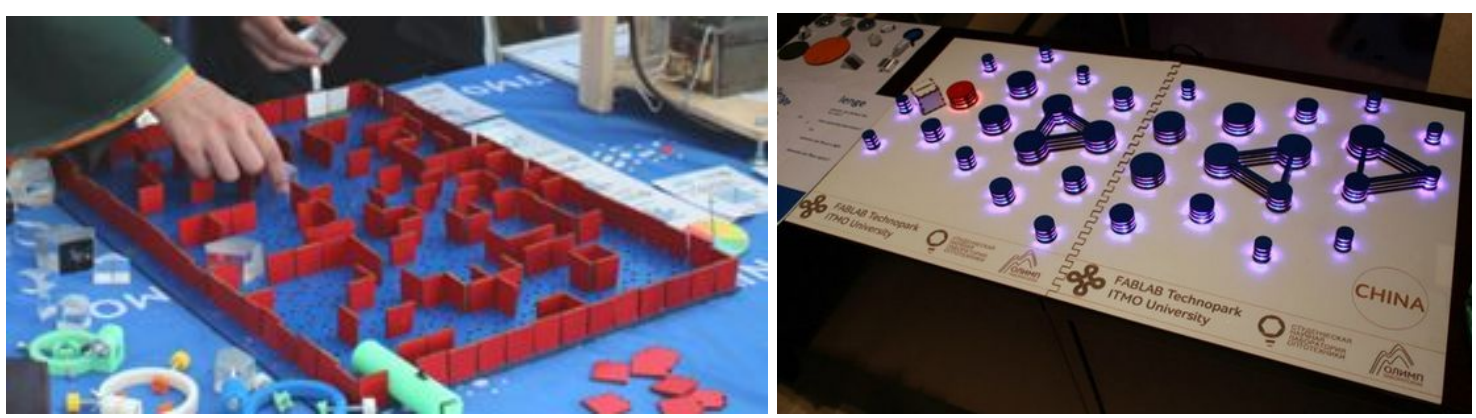

Figure 8. The sample of MP and DU labyrinth

\section{CONCLUSIONS}

The two labyrinths presented in this paper are intended to teach the basic rules of light and the principles of working with optical prisms which are commonly found in all manner of optical systems and devices in wide use today. The first type of labyrinth is a valuable addition to the educational process, while the second one has had successful usage in social events targeted at popularizing optics in a fun, engaging, and informative way. Additionally, the labyrinth project itself has been an interesting scientific project and learning opportunity for the students who went through the design and development efforts for it. We believe that increasing the number of games and puzzles used to explain physical phenomena will lead to more effective and more inclusive education in many areas of science.

\section{REFERENCES}

[1.] Tolstoba N. D., Saitgalina A.K., Abdula P.A., Butova D.V. Student research laboratory for optical engineering. Proceedings of SPIE, 2015, Vol. 9793, pp. 97931Y

[2.] Saitgalina A.K., Tolstoba N. Discover the power of light: student research laboratory for optical engineering at ITMO University. Proceedings of SPIE, 2016, Vol. 9946-38, pp. 994611

[3.] Ivashchenko M., Bodrov K., Tolstoba N. Educational area for learning of optics and technologies: union of Open Laboratories of Ideas, Methods and Practices (OLIMP). Proceedings of SPIE, IET, 2016, Vol. 9946, pp. 994613

[4.] Tolstoba N., Voznesenskaya A., Orekhova M. Practical training: from ideas to optical device. Proceedings of SPIE, IET, 2016, Vol. 9946, pp. 994614

[5.] Bakholdin A., Ezhova K., Voznesenskaya A., Ivanova T., Romanova G., Tolstoba N. Collaboration between Applied and computer optics department of ITMO University with industry's leading manufacturers//Proceedings of SPIE, IET 2015, Vol. 9793, pp. 97932F

[6.] Voznesenskaya A., Romanova G., Bakholdin A., Tolstoba N., Ezhova K. Short educational programs in optical design and engineering//Proceedings of SPIE, IET - 2016, Vol. 9946, pp. 994619 